\title{
Impacts of 20th century aerosol emissions on the South Asian monsoon in the CMIP5 models
}

\author{
L. Guo ${ }^{1}$, A. G. Turner ${ }^{1,2}$, and E. J. Highwood ${ }^{1}$ \\ ${ }^{1}$ Department of Meteorology, University of Reading, Earley Gate, P.O. Box 243, Reading, RG6 6BB, UK \\ ${ }^{2}$ NCAS-Climate, Department of Meteorology, University of Reading, Earley Gate, P.O. Box 243, Reading, RG6 6BB, UK \\ Correspondence to: L. Guo (1.guo@reading.ac.uk)
}

Received: 10 October 2014 - Published in Atmos. Chem. Phys. Discuss.: 3 December 2014

Revised: 8 May 2015 - Accepted: 12 May 2015 - Published: 11 June 2015

\begin{abstract}
Comparison of single-forcing varieties of 20th century historical experiments in a subset of models from the Fifth Coupled Model Intercomparison Project (CMIP5) reveals that South Asian summer monsoon rainfall increases towards the present day in Greenhouse Gas (GHG)-only experiments with respect to pre-industrial levels, while it decreases in anthropogenic aerosol-only experiments. Comparison of these single-forcing experiments with the all-forcings historical experiment suggests aerosol emissions have dominated South Asian monsoon rainfall trends in recent decades, especially during the 1950s to 1970s. The variations in South Asian monsoon rainfall in these experiments follows approximately the time evolution of inter-hemispheric temperature gradient over the same period, suggesting a contribution from the large-scale background state relating to the asymmetric distribution of aerosol emissions about the equator.

By examining the 24 available all-forcings historical experiments, we show that models including aerosol indirect effects dominate the negative rainfall trend. Indeed, models including only the direct radiative effect of aerosol show an increase in monsoon rainfall, consistent with the dominance of increasing greenhouse gas emissions and planetary warming on monsoon rainfall in those models. For South Asia, reduced rainfall in the models with indirect effects is related to decreased evaporation at the land surface rather than from anomalies in horizontal moisture flux, suggesting the impact of indirect effects on local aerosol emissions. This is confirmed by examination of aerosol loading and cloud droplet number trends over the South Asia region. Thus, while remote aerosols and their asymmetric distribution about the equator play a role in setting the inter-hemispheric temperature distribution on which the South Asian monsoon, as one
\end{abstract}

of the global monsoons, operates, the addition of indirect aerosol effects acting on very local aerosol emissions also plays a role in declining monsoon rainfall. The disparity between the response of monsoon rainfall to increasing aerosol emissions in models containing direct aerosol effects only and those also containing indirect effects needs to be urgently investigated since the suggested future decline in Asian anthropogenic aerosol emissions inherent to the representative concentration pathways (RCPs) used for future climate projection may turn out to be optimistic.

In addition, both groups of models show declining rainfall over China, also relating to local aerosol mechanisms. We hypothesize that aerosol emissions over China are large enough, in the CMIP5 models, to cause declining monsoon rainfall even in the absence of indirect aerosol effects. The same is not true for India.

\section{Introduction}

The monsoon is vital to society in South Asia since more than a billion people there rely on it to supply over $80 \%$ of annual rainfall between the months of June and September. The increasing population, with its need for rainfed or irrigated agriculture and its rapidly developing industry, need accurate information on how the monsoon varies on long and short timescales and reliable future projections. However, even the current generation of state-of-the-art coupled ocean-atmosphere models participating in the Fifth Coupled Model Intercomparison project (CMIP5) suffer large biases in the region (Sperber et al., 2013), likely due to poor parameterizations and entirely missing processes, in addition to 
poorly represented observed trends in monsoon rainfall when take as a whole (Saha et al., 2014; Sabeerali et al., 2014; Salzmann et al., 2014).

Analysis of India's relatively long gauge-based observational record, dating back to at least the 1870 s, reveals considerable decadal and longer variations (Turner and Annamalai, 2012; Krishnamurthy and Goswami, 2000). However, given increases in GHG (Greenhouse Gas) emissions over recent decades, the lack of an upward trend is puzzling (Goswami et al., 2006), as monsoon rainfall tends to increase with an increase moisture source from the warmer Indian Ocean (e.g. Douville et al., 2000). The analysis of Goswami et al. (2006) focused on the central India portion of $1^{\circ}$-gridded data (Rajeevan et al., 2006) and found no overall trend in monsoon rainfall since the 1950s, itself a competition between decreasing frequency of light-to-moderate rainfall and increasing frequency of extreme heavy rainfall. Dash et al. (2009) noted the same decrease in light-to-moderate events when looking at the whole of India in the same data set. However, other authors have noted overall negative trends. Ramanathan et al. (2005) found negative trends particularly in July up to 2000, while with data up to 2004 Gautam et al. (2009) found significant declining trends from July to September over India. Meanwhile, a recent comparison of trends in four different gridded rainfall data sets for India noted area-averaged rainfall decreases since the 1950s (Bollasina et al., 2011), although with considerable spatial differences (especially in north-eastern peninsular India) and relatively few gridpoints yielding statistically significant trends. Negative trends in the orographic rainfall near the Western Ghats on the west coast of India in APHRODITE gridded gauge data have been attributed to weakening of the monsoon circulation (Krishnan et al., 2013).

Anthropogenic aerosol emissions have the potential to limit monsoon rainfall. Aerosol emissions have been rising in India since the 1950s due to expansion of industry and the rapidly increasing population which uses cooking fires. Remote sensing and ground-based observations applied to aerosol measurements from the mid-1980s have shown an increasing trend in aerosol loading and aerosol optical depth (AOD) (Moorthy et al., 2013; Acharya and Sreekesh, 2013). Maximum concentrations are found pushed up against the foothills of the Himalayas in the northern plains of India during pre-monsoon season (Lau et al., 2006), and remain strong during June and July (Lau et al., 2008).

Aerosol has the potential to offset the impact of GHG over South Asia. By scattering and absorbing solar radiation, aerosol reduces incoming solar radiation at the surface and weakens the meridional thermal contrast (in part consisting of a land-sea temperature contrast at the surface) via the aerosol direct effect (Charlson et al., 1992). By acting as cloud condensation nuclei (CCN), increasing aerosol concentrations can also reduce cloud droplet size, increase cloud albedo (Twomey, 1977) and reduce drizzle (Albrecht, 1989) via aerosol indirect effects. Ramanathan et al. (2005) sug- gested that aerosols may have already masked up to $50 \%$ of the potential GHG-related surface warming by cooling the northern Indian Ocean, which may reduce monsoon rainfall. In future climate projections, comparison of experiments including and excluding sulphate aerosols has shown that when included, more restrained increases in monsoon rainfall occur (Meehl et al., 2007). Ramanathan et al. (2005) suggest that both direct and indirect effects of aerosol can act to spin down summer monsoon circulation, reducing low-level moisture and rainfall.

Recently, Bollasina et al. (2011) used the GFDL-CM3 coupled model to suggest that decreasing monsoon rainfall over a small region of northern India since the 1950s could be attributed to increasing global emissions of anthropogenic aerosol, particularly implicating the indirect effect. Other studies using GCMs found consistent South Asian monsoon rainfall decreases since the 1950s (Cherian et al., 2013; Devara and Manoj, 2013; Sajani et al., 2012). However one must question the cause of rising trends in monsoon rainfall over the first half of the 20th century in the absence of large anthropogenic GHG or aerosol forcing (see e.g. Fig. 2 in Turner and Annamalai, 2012).

At the hemispheric scale, Kitoh et al. (2013) have demonstrated multi-model ensemble mean decreases in northernhemisphere (NH hereafter) monsoon rainfall over the 20th century in historical integrations, consistent with observed measures and arguments pertaining to aerosol. This was explained in more detail by Polson et al. (2014) who attributed the reduced $\mathrm{NH}$ monsoon precipitation to increasing aerosol emissions in a subset of the CMIP5 experiments, relating to a temperature contrast between the $\mathrm{NH}$ and Southern Hemisphere (SH). Such changes in interhemispheric temperature gradient are also known to affect the $\mathrm{NH}$ monsoons on decadal timescales (Wang et al., 2013). In the future, RCP4.5 and RCP8.5 scenarios will both show increases in NH monsoon rainfall, consistent with the dominance of GHG forcing on the monsoon in those emissions scenarios (Kitoh et al., 2013).

The CMIP3 coupled GCMs used in the IPCC AR4 rarely incorporated the indirect effects of aerosol. But increasing complexity of aerosol parameterizations and emissionsbased inclusion of aerosol loading in the CMIP5 models yields new opportunities. Ekman (2014) has shown that with increasingly sophisticated parameterization of aerosol-cloud interactions, the bias of the modelled global mean and zonal mean surface temperature trends between 1965-2004 is reduced compared with observations. However, there is still considerable model diversity as to which indirect effects are included and how they are parameterized (see e.g. Wilcox et al., 2013; Ekman, 2014). Furthermore, rather than by prescribing AOD, aerosols are now generally included via emissions at source, which leads to considerable diversity in aerosol burden. The societal impact of any change in South Asian monsoon rainfall requires us to understand the role of aerosol in producing uncertainty in recent historical 
model simulations of the monsoon and their future projections. Given the large emissions from sources local to South Asia as well as the known impacts of aerosol at the hemispheric scale, there is a need also to understand the relative impact of local and remote drivers of the monsoon from aerosol forcing.

This paper will compare the impact of GHG forcing with that of anthropogenic aerosol on the South Asian monsoon in historical experiments in CMIP5 and the role of direct and indirect aerosol effects. We will also discuss the implications of this for future projections of monsoon rainfall. Various authors have questioned the ability of CMIP5 models to capture observed monsoon rainfall trends over India (e.g. Saha et al., 2014) and therefore the reliability of CMIP5 at making projections of future monsoon rainfall (Ramesh and Goswami, 2014; Sabeerali et al., 2014). In our study we shall demonstrate that it is only when aerosol indirect effects are included, and therefore when more physical processes are being represented, that these models are able to capture the observed trends. Section 2 introduces the CMIP5 data sets and statistical methods to be used in this study. Section 3 compares the impacts of aerosol versus those of GHG on the monsoon and then compares the impact of the direct effect with indirect effect in Sect. 4. Implications of our results on future projections of the monsoon and more general conclusions are given in Sect. 5.

\section{Data and methods}

The long-term historical integrations from the Fifth Coupled Model Intercomparison Project (CMIP5 Taylor et al., 2012) are used in this study. The historical run is forced by observed atmospheric composition changes (including GHG, natural and anthropogenic aerosols and volcanic forcing), solar variations and time-evolving land cover in a bid to simulate the observed climate of the recent historical period. To calculate the multi-model ensemble mean (MME-mean hereafter) and to perform model comparisons we use the common period of 1861-2005.

Table 1 lists information of 24 participating models. In addition to the aforementioned historical experiments, eight models highlighted in Table 1 also have available singleforcing scenarios of the historical period, that is, instead of being forced by all atmospheric composition changes and land cover changes, only one change or a subset of changes is applied to drive the model. These single forcing experiments are useful to detect changes in climate and attribute them to changes in forcing agent (e.g. Wilcox et al., 2013; Jones et al., 2011), and include GHG-only and anthropogenic aerosol-only experiments. Since CMIP5 model experiments do not provide a uniform set of diagnostic output variables, Table 1 also lists the availability of diagnostics for aerosol loading (column-integrated mass of aerosol), fractional lowcloud cover and cloud droplet number. To calculate devi- ations from the long-term mean, we use the pre-industrial control integrations, in which forcing terms are fixed and from which the historical integrations are initialized. Thus we present Figs. 1 and 2 as deviations from the pre-industrial long-term mean.

Where appropriate for spatial analysis, model data have been bilinearly interpolated to a common horizontal output grid of $2.8^{\circ} \times 2.8^{\circ}$. We produce a time series for South Asia by area-averaging over $10-35^{\circ} \mathrm{N}, 70-90^{\circ} \mathrm{E}$. Results shown in this study are calculated from the MME-mean. As the modelling groups submitted a different number of samples for each model integration, to make sure each model is weighted evenly in the MME-mean, a mean is first applied to models having more than one sample. To demonstrate that the signal from the MME-mean is robust, we apply permutation and binomial significance tests. The permutation test is applied when the sample size is small, while the binomial test is used to indicate where a statistically significant number of models agree on the sign of change.

\subsection{Permutation test}

The permutation test is a non-parametric test and by definition does not rely on assumptions of parametric distributions. The test is performed by constructing an artificial data set from the original data by resampling numerous times. Each artificial data set can then be compared to the original data using the desired test statistic, and the test statistic is itself then compared to the test statistics generated from comparisons in the original data (Wilks, 1995).

The change of rainfall is defined as $\Delta R=R(t)-R_{\mathrm{PI}}$, where PI is the pre-industrial period defined as 1861-1880 and $R(t)$ is rainfall at time $t$. We use the permutation test to examine the difference between rainfall changes in models including indirect effects and in those including direct effects only, computing a difference in test statistic: $m=$ $\left|\Delta R_{\text {indirect }}-\Delta R_{\text {direct }}\right|$.

Under the null hypothesis that the two groups have the same change, $m$ should be zero. If models including indirect effects do affect rainfall over South Asia in a different manner to those including only the direct effect, $m$ should be larger than zero. The artificial data set, known as the null distribution of the test statistic, is constructed by sampling 10000 permutations of $n=24$ data points (CMIP5 models) into two batches of $n_{1}=15$ and $n_{2}=9$ as in Table 1. For each permutation, $m$ is calculated and denoted as $m_{\text {calc. }}$. At the $90 \%$ significance level, if the real value $m_{\text {real }}$ is larger than 9000 of these $10000 \mathrm{~m}_{\text {calc }}$, then the null hypothesis is rejected.

\subsection{Binomial test}

We use the binomial test to examine the significance of the sign of change in rainfall maps between the present and preindustrial periods. The binomial test is a parametric test re- 
Table 1. CMIP5 models used in this study. Models shown in bold italic are also available for single forcing runs. Ticks in the table indicate data availability under those headings.

\begin{tabular}{lcccc}
\hline Model & Indirect effects & \multicolumn{3}{c}{$\begin{array}{c}\text { Diagnostic } \\
\text { availability }\end{array}$} \\
\cline { 3 - 5 } & & \multicolumn{3}{c}{} \\
\cline { 3 - 5 } parameterized? & aerosol loading & low cloud cover & cloud droplet number \\
CESM1-CAM5 & Y & $\checkmark$ & $\checkmark$ & \\
CNRM-CM5 & Y & & $\checkmark$ & \\
CSIRO-Mk3.6.0 & Y & & $\checkmark$ & $\checkmark$ \\
GFDL-CM3 & Y & $\checkmark$ & $\checkmark$ & \\
HadGEM2-CC & Y & $\checkmark$ & $\checkmark$ & $\checkmark$ \\
HadGEM2-ES & Y & $\checkmark$ & $\checkmark$ & \\
INMCM4 & Y & $\checkmark$ & $\checkmark$ & \\
IPSL-CM5A-LR & Y & & $\checkmark$ & \\
IPSL-CM5A-MR & Y & $\checkmark$ & $\checkmark$ & \\
MIROC5 & Y & $\checkmark$ & $\checkmark$ & \\
MIROC-ESM & Y & $\checkmark$ & $\checkmark$ & \\
MIROC-ESM-CHEM & Y & $\checkmark$ & $\checkmark$ & \\
MRI-CGCM3 & Y & $\checkmark$ & $\checkmark$ & \\
NorESM1-M & Y & $\checkmark$ & $\checkmark$ & \\
\hline BCC-CSM1.1 & Y & $\checkmark$ & $\checkmark$ & \\
BNU-ESM & N & & & \\
CCSM4 & N & & & \\
CESM1-BGC & N & & & \\
EC-EARTH & N & & & \\
FIO-ESM & N & & & \\
GFDL-ESM2G & N & & & \\
GFDL-ESM2M & N & & & \\
MPI-ESM-LR & N & & & \\
\hline
\end{tabular}

lying on the binomial distribution, appropriate for outcomes where only one or the other of two mutually exclusive and collectively exhaustive events will occur. The relevant probability distribution function is:

$\operatorname{Pr}\{X=x\}=\left(\begin{array}{l}N \\ x\end{array}\right) p^{x}(1-p)^{N-x}, x=0,1, \ldots, N$

where $N$ is the total number of events. $X$ is the expected number of event occurrences from 0 to $N$ and $p$ is the probability of occurrence. In this study, $N$ is the total number of models used. Under the null hypothesis each sign of rainfall change occurs with equal likelihood, i.e., $p=0.5$. For grid points where the MME-mean rainfall change is positive, the number of models from which the rainfall change is positive is counted, and denoted as $n$. The probability that $n$ or more models show positive rainfall change is computed as:

$p=\sum_{x=n}^{N} \operatorname{Pr}\{X=x\}=\sum_{x=n}^{N}\left(\begin{array}{l}N \\ x\end{array}\right) p^{x}(1-p)^{N-x}$,
$x=n, \ldots, N$.

If $p \leq 0.1$, then the null hypothesis is rejected at the $90 \%$ level. An analogous process is applied for negative changes.

\section{Aerosol impacts on rainfall changes over South Asia}

In this section we describe the relative effects of aerosol versus GHG emissions during the 20th century on South Asian monsoon rainfall, followed by comparing models including indirect aerosol effects and those including direct effects only.

\subsection{Relative impacts of GHG vs. aerosol emissions over South Asia for the historical period}

To compare the relative impacts of GHG and aerosol emissions on the South Asian monsoon from the pre-industrial period to the present, we show the time series of area-mean South Asia rainfall during June-September (JJAS) in the historical all-forcings, aerosol-only and GHG-only experiments in Fig. 1a.

Despite much inter-model variation (shadings), the MMEmeans (thick lines) for each experiment in Fig. 1a show similar long-term evolution of monsoon rainfall in all three experiments during the late 19th century, with no obvious large trends over South Asia.

The broad similarity of the evolving MME-mean monsoon rainfall across the three experiments in the first half of 


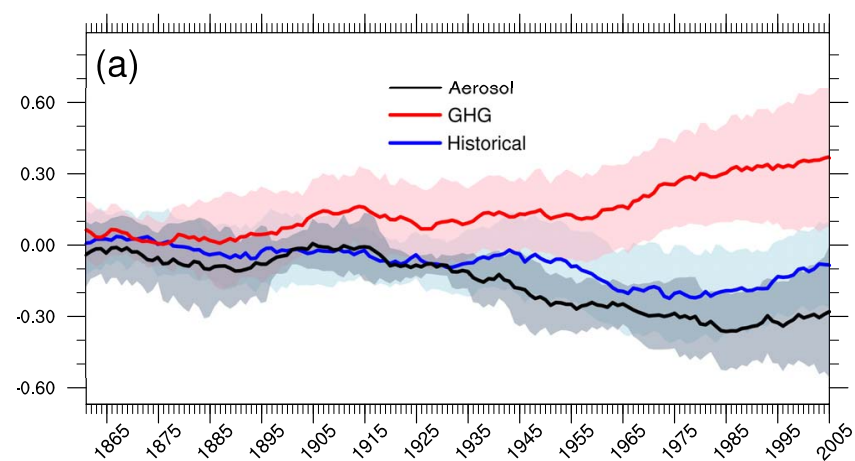

The most notable feature of the late 20th century in Fig. 1a is the close resemblance between the evolution in the allforcings experiment and that in the aerosol-only experiment. This similarity indicates that aerosol forcing is playing a greater role than GHG forcing over South Asia during the summer monsoon season in the late 20th century. This result from the MME-means is consistent with the single-model study of Bollasina et al. (2011) using GFDL-CM3, in which observed declines in South Asian monsoon rainfall since the 1950s were attributed to increasing concentrations of aerosol. We note that recent studies, e.g., Salzmann et al. (2014) have argued that the model internal variability can play as important a role as aerosol forcing over central-northern India. The South Asian monsoon does undergo variations on decadal timescales, for example related to the Pacific Decadal Oscillation (PDO). However, the design of the CMIP5 20th century historical experiments is such that they are not initialised to ocean conditions. Therefore any variations in the PDO in the CMIP5 models will not be in phase either to observations, or each other. The multi-model ensemble mean approach that we have used means that we will emphasise the variations in the monsoon common to all models and other variability will be smoothed out. The declining trend in the CMIP5 MMEmean is not found in CMIP3 (Fan et al., 2010).

Given the known role of hemispheric-wide forcings on the 1. (a) JJAS rainfall from 1861-2005 averaged over South Asia $\left(10-35^{\circ} \mathrm{N}, 70-90^{\circ} \mathrm{E}\right)$ in the CMIP5 all-forcings historical experiment (blue), GHG-only historical experiment (red) and the aerosol-only historical experiment (black). The thick lines show MME-means with a 21-year running mean applied, while the pale envelope indicates the $\pm 1 \sigma$ range from the mean. Only eight models are used in constructing this figure (see Sect. 2): CanESM2, CCSM4, CSIRO-Mk3.6.0, GFDL-CM3, GFDL-ESM2M, HadGEM2-ES, IPSL-CM5A-LR and NorESM1$M$. The curves are centred around zero by removing the mean rainfall from pre-industrial control runs (piControl) of the same models. Units are $\mathrm{mmday}^{-1}$. (b) Same as (a) but for the global mean and annual mean land-sea surface temperature contrast from 18612005. Units are $\mathrm{K}$.

the time series is consistent with weak variations in anthropogenic emissions of aerosol and GHGs. However, from the early 20th century, summer monsoon rainfall in the GHGonly experiment becomes greater than in the aerosol-only or all-forcings experiments, consistent with increasing GHG emissions since the pre-industrial and results of previous studies showing the impact of increased $\mathrm{CO}_{2}$ on the monsoon (as reviewed in Turner and Annamalai, 2012). Clear differences emerge from the 1930s onwards: tending in opposite directions between GHG-only and aerosol-only experiments. With higher GHG concentrations in the atmosphere, mean rainfall in the GHG-only experiment increases as much as $0.3 \mathrm{~mm} \mathrm{day}^{-1}$ (36 mm over the season) by 2005 , while with increasing global aerosol emissions in the aerosolonly experiment, mean monsoon rainfall decreases by around $0.3 \mathrm{~mm}$ day $^{-1}$. NH monsoons, either internally generated (Wang et al., 2013) or relating to aerosols (Polson et al., 2014), we also look at a measure of large-scale thermal contrast here. We choose a measure of land-sea thermal contrast, which is known to increase in the future yet uncorrelated with global mean temperature change in climate models (Joshi et al., 2013). Given the asymmetric distribution of land on Earth's surface, landsea contrast will also project onto the inter-hemispheric temperature gradient. Figure $1 \mathrm{~b}$ shows the global, annual-mean land minus sea temperature contrast for the eight CMIP5 models available for the all-forcings historical experiment as well as the single-forcing experiments (see Table 1). Due to the differential warming between land and sea in response to greenhouse warming, there is an increasing land-sea contrast in the GHG-only experiment. In the aerosol-only experiment, however, it decreases, reflecting the dominance of aerosol emissions in the NH during the late 20th century. The effects of both aerosol and GHG are combined in the all-forcings experiment, showing the dominance of different effects at different times. Before the 1950s, the land-sea contrast is dominated by the GHG forcing, an expected result of greenhouse warming. By the 1950s, aerosol forcing dominates (relative cooling of the $\mathrm{NH}$ ), reflecting industrialisation and strong, particularly sulphate, emissions from North America, Europe and South and East Asia. More restrictive legislation in Europe and North America led to declining emission sources from the 1970s, leading to GHG regaining their role as the dominant forcing of land-sea contrast from the 1970s onwards. Since land-sea contrast is a fundamental mechanism driving the monsoon circulations, these variations are partly 
reflected in the all-forcings South Asian monsoon precipitation curve of Fig. 1a.

Therefore increasing aerosol emissions could act remotely, setting the large-scale background in which the South Asian monsoon operates. Since the provision of single forcing runs is limited, we next examine all available all-forcings historical runs listed in Table 1 according to the type of aerosol effects included.

\subsection{Comparison of aerosol direct and indirect effects over South Asia in the historical period}

To determine if the type of aerosol effects that are included in models has any impact on the aerosol-related downward trend in monsoon rainfall in the late 20th century, and to improve the sample size used for analysis, the 25 CMIP5 allforcings historical experiment models listed in Table 1 are divided into two groups: those models parameterizing the aerosol direct effect only (no indirect effects) and models parameterizing both direct and indirect effect (indirect effects are included). With the greater number of model samples, the robustness of the findings can be tested more easily using statistical analysis.

Figure 2a shows the evolution of South Asian monsoon rainfall over the same period as Fig. 1a. Both the directonly models and those also including indirect effects show a decrease in monsoon rainfall since 1950, in response to increases in anthropogenic aerosol emissions. However, when aerosol indirect effects are also included, the rainfall decrease over the period is larger and more persistent than in models where only the direct effect of aerosols is included. The permutation test has been applied as explained in Sect. 2, indicating significant differences particularly in the late 20th century.

There is no so significant difference in the pre-industrial period during which anthropogenic greenhouse gases and aerosol emissions were small. Without strong external forcing, therefore, the difference in rainfall is dominated by internal variability. However, a persistent and significant difference between the two model groups emerges from the late 1970s onwards, which indicates that the inclusion of aerosol indirect effects in models may play an important role in reducing monsoon rainfall. This finding warrants urgent further study to examine the nature of the included aerosol indirect effects and their representation in models. As earlier, we measure the change in global-scale land-sea temperature contrast in the two groups of models, as shown in Fig. $2 b$. The land-sea contrast has a larger decrease from the 1950s to the mid-1970s in the models including aerosol indirect effects. This indicates that, in response to the increase of $\mathrm{NH}$ aerosols, the enhancement of aerosol effects leads to greater relative cooling of the $\mathrm{NH}$, consistent with the downward trend in monsoon rainfall seen in Fig. 2a.

We now examine the spatial pattern of rainfall change between the pre-industrial period and present day in the MME-
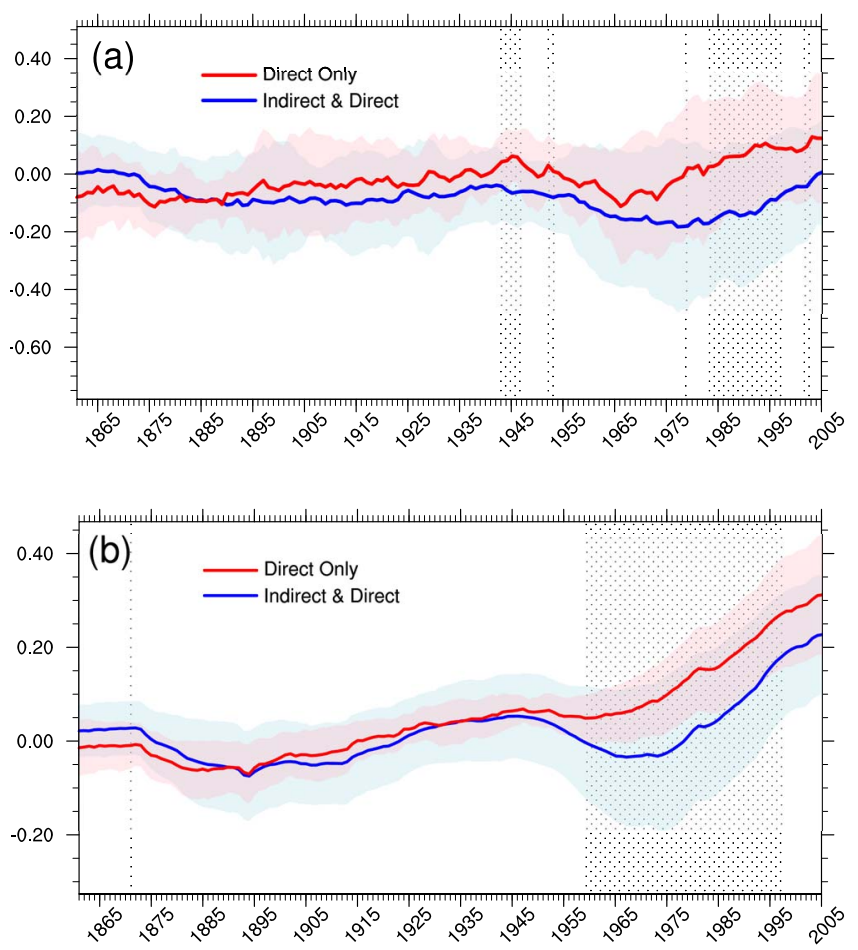

Figure 2. (a) JJAS rainfall from 1861-2005 averaged over South Asia $\left(10-35^{\circ} \mathrm{N}, 70-90^{\circ} \mathrm{E}\right)$ in 24 CMIP5 models which have allforcing historical experiments. The models are divided into two groups, the direct effect only models (red) and the indirect effect included models (blue), as shown in Table 1. The thick lines show MME-means with a 21-year running mean applied, while the pale envelope indicates the $\pm 1 \sigma$ range from the mean. Differences exceeding the $90 \%$ significant level using a permutation test are stippled. The curves are centred around zero by removing the mean rainfall from pre-industrial control runs (piControl) of the same models. Units are mmday ${ }^{-1}$. (b) Same as (a) but for the global mean and annual mean land-sea surface temperature contrast from 1861-2005. Units are K.

mean for the all-forcings historical experiment and for the direct and indirect groups of models in Fig. 3.

We start with the similarities between the different groups. Over Southeast and East Asia, the rainfall signals are generally consistent between the models including indirect effects and those including direct effects only. Southeast Asia and the Maritime Continent feature declining rainfall in the CMIP5 models over the historical period of up to $0.5 \mathrm{~mm} \mathrm{day}^{-1}$. The decrease is stronger in the models including indirect effects, suggesting that inclusion of these effects (for example, interaction of aerosol and low-cloud leading to an increased number of cloud droplet and reduced radiative forcing at the surface) acts to enhance the decline in rainfall. However, the suggestion is that aerosol direct effects in combination with prescribed local emissions are enough in these regions to reduce monsoon rainfall. In East Asia the situation is the same, particularly in China south 


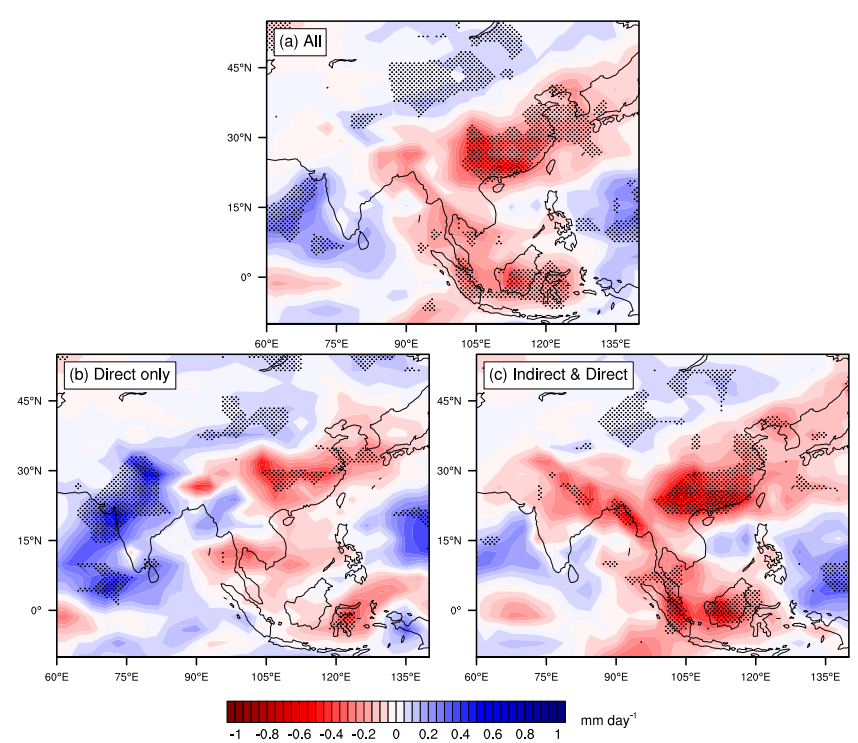

Figure 3. Changes of JJAS rainfall between present-day and preindustrial periods (1986-2005 minus 1861-1880) in MME-means of the CMIP5 all-forcings historical experiment: (a) all 24 CMIP5 models used in this study; (b) nine models parameterizing only the aerosol direct effect; (c) 15 models including both aerosol direct and indirect effects. Changes exceeding the $90 \%$ significance level using the binomial test are stippled. Units are $\mathrm{mm}^{\mathrm{day}}{ }^{-1}$.

of the Yangtze river, with significant decreases in rainfall in the present day. Again, the signal is stronger and more widespread when indirect aerosol effects are included. These results for China are consistent with our findings in Guo et al. (2013), which, although only for late summer, showed in the HiGAM AGCM that increasing anthropogenic concentrations of anthropogenic aerosol reduced the strength of East Asian monsoon rainfall. Guo et al. (2013) also noted that inclusion of aerosol indirect effects enhanced this reduction. Note that this rainfall change over much of East Asia is inconsistent with the recent observational trend (Zhai et al., 2005), which shows a dipole pattern of decreases in the north and increases in the south. While the multi-model trend discussed in this paper is over the centennial scale from the pre-industrial to present-day periods and is dominated by external anthropogenic forcing, the short length of reliable precipitation measurements for China (from 1950 onwards) means that any such observational trend may be subject to unforced decadal signals. A further interpretation is that the observed dipole trend, with rainfall increases in the south at the expense of decreases further north, represents monsoon weakening, since the circulation does not penetrate so far north (Ding et al., 2008). Further evidence from horizontal (see later in Fig. 4) and vertical (not shown) moisture fluxes show that the contribution of aerosol forcing to the modelled weakening trend over China comes in the form of local evaporation decreases, causing aerosol-induced reductions in surface solar radiation.

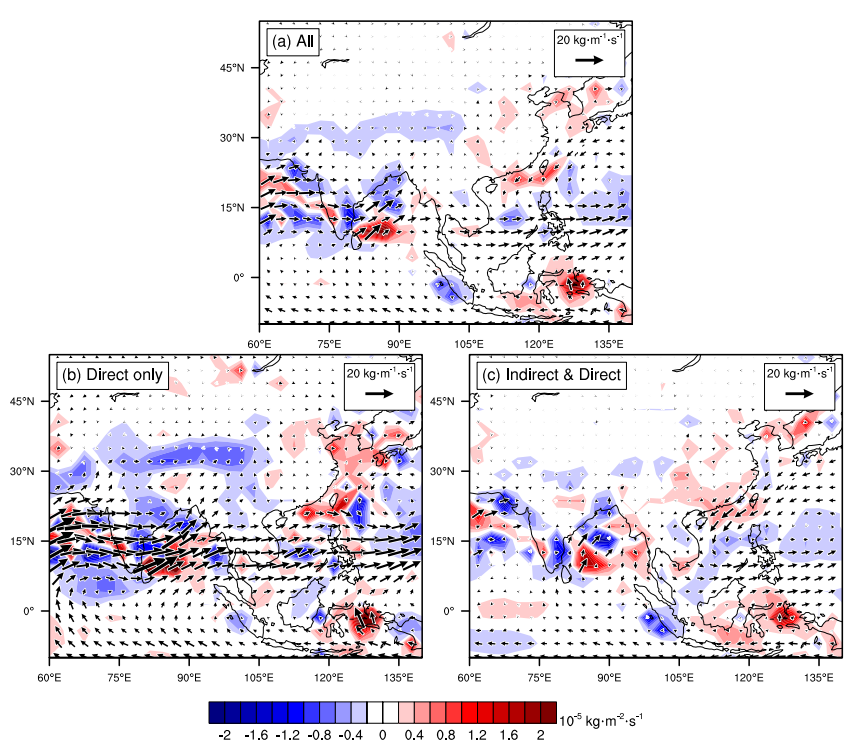

Figure 4. Same as Fig. 3 but showing moisture flux vertically integrated from $1000-700 \mathrm{hPa}$ (vectors) and its divergence (shading). The unit vector is $20 \mathrm{~kg} \mathrm{~m}^{-1} \mathrm{~s}^{-1}$.

We now focus on the large differences in response over South Asia. Aside from the drying over Bangladesh at the head of the Bay of Bengal, the MME-mean of all models (Fig. 3a) shows only small, insignificant changes in rainfall. In models containing only aerosol direct effects (Fig. 3b), rainfall changes over India are strongly positive by up to $0.5 \mathrm{~mm} \mathrm{day}^{-1}$. Such increases in rainfall are not physically consistent with the direct effects of aerosol in response to increasing emissions, but they are consistent with the increase in GHG emissions from the pre-industrial to present-day period. The changes are concentrated in branches particularly over northern India and over the southern tip, consistent with individual model studies for increasing GHG forcing (e.g. Turner et al., 2007, in HadCM3) or in multi-model means (Meehl et al., 2007).

However, in the MME-mean difference in models including aerosol indirect effects, (Fig. 3c), the sign of rainfall change is negative, most strongly in the northern plains of India south of the Himalayan foothills. This change is also significant at the $90 \%$ level using a binomial test. Previous studies have also found a strong rainfall change signal over this region in response to aerosol forcing, notably Lau et al. (2006), pointing out that aerosols accumulate against the southern slopes of the Himalayas, and Bollasina et al. (2011) who used a single-model to attribute decreases in northern India precipitation in recent observations to increasing concentrations of aerosol. In particular, Bollasina et al. (2011) blamed the indirect effects of aerosol.

To investigate the mechanisms involved, the corresponding change of moisture transport is shown in Fig. 4. Over the Maritime Continent, moisture is usually transported from the 
West Pacific Warm Pool on prevailing easterlies. However, for both direct-only and indirect groups over this region, a westerly-to-southwesterly transport anomaly indicates moisture transport out of this region, and contributing to the reduced rainfall. The similarity in moisture transport between the two groups of models is also shown over East Asia, with a cyclonic moisture transport anomaly bringing dry midlatitude air and indicating the weakening of monsoon circulation. A moisture flux divergence anomaly over the east coast of China and Korean Peninsula corresponds to rainfall decline over this region. The lack of divergent signals over China (as we would expect given the rainfall decrease in Fig. 3) suggests rainfall changes are locally driven rather than via changes in circulation. This is supported by reduced latent heat flux at the surface (not shown).

The largest discrepancy between the two groups is over South Asia, the stronger moisture flux from the Arabian Sea indicates a stronger monsoon in the direct-only group of models, corresponding to a rainfall increase along the west coasts of India and Burma in Fig. 3b. In the models including indirect effects, however, there is not an obvious change in moisture transport. A small moisture flux convergence at the head of the Bay of Bengal is inconsistent with the rainfall reduction shown in Fig. 3c. This indicates that, like China, local factors play a more important role than remote effects acting on the circulation to reduce rainfall in the indirect models. Indeed, examination of latent heat flux at the surface indicates strong decreases for the indirect models over South Asia. Local aerosol indirect effects are a key potential factor.

Next we consider the necessary mechanisms for local indirect effects to be driving monsoon rainfall changes over South Asia.

\section{Local aerosol indirect effects in CMIP5 models over South Asia}

As shown in the previous section, aerosol indirect effects play a dominant role in reducing rainfall over South Asia under rising emissions of anthropogenic aerosol. Since aerosol indirect effects are the result of aerosol-cloud interactions, the colocation of aerosol and cloud (particularly low cloud) is crucial for their operation.

We focus on local aerosol indirect effects over South Asia. Local aerosol loading change is not necessarily attributed to co-located changes in aerosol emissions. However, over South Asia, studies show that local aerosol emissions are dominant (Misra et al., 2014). Figure 5a-c show the spatial patterns of aerosols (sulphate and black carbon) loading and low cloud fraction, where those diagnostics are available in the indirect models as indicated in Table 1. In models including aerosol indirect effects, the heaviest aerosol loadings are found over the northern plains of India and the Himalayan foothills. As mentioned above, collocation with low cloud is
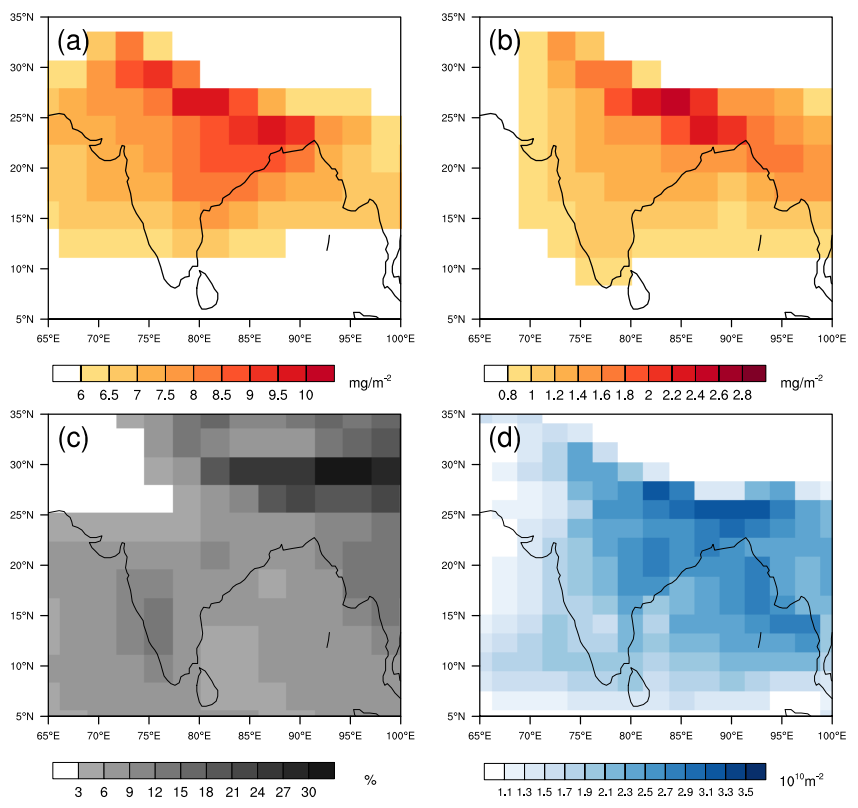

Figure 5. (a, b) JJAS averages over 1986-2005 of sulphate and black carbon aerosol loadings in aerosol indirect effect included models (units are $\mathrm{mg} \mathrm{m}^{-2}$ ); (c) JJAS averages over 1986-2005 of cloud fraction from $500 \mathrm{hPa}$ to the surface of the aerosol indirect effect included models (units are \%); and (d) JJAS averages column integral cloud droplet number change from the pre-industrial to present day (1986-2005 minus 1861-1880) in aerosol indirect effect included models (units are $10^{10} \mathrm{~m}^{-2}$ ).

vital for the aerosol indirect effect to interact with the high aerosol loadings. Figure 5c shows roughly comparable lowcloud distributions in the models including aerosol indirect effects. While the maximum in low cloud concentration is not situated over the strongest aerosol loadings in Fig. 5a, there is still a coverage of around $10 \%$ over northern India, reaching over $20 \%$ in the east.

Since sulphate aerosols act as cloud condensation nuclei, aerosol indirect effects are generated because cloud droplet number increases and clouds become more reflective to solar radiation. Figure 5d shows a strong increase in cloud droplet number between the pre-industrial and present day from those models in the indirect group in which this diagnostic is available (see Table 1). The cloud droplet number has a larger increase over the northern plains of India, Himalayan foothills and the head of the Bay of Bengal, where aerosols and low cloud are collocated. We note that the spatial changes of cloud droplet number match the pattern of rainfall change in the indirect models (Fig. 3c), giving us confidence that decreasing rainfall over South Asia is related to local aerosol indirect effects. 


\section{Conclusions and discussions}

In this study we have examined the relative impact of anthropogenic aerosol versus greenhouse gas emissions over the historical period on the South Asian monsoon in the CMIP5 integrations, and the difference in response between models parameterizing direct radiative effects of aerosol only and those also including indirect effects. This is motivated by the apparent decline in South Asian monsoon rainfall since the 1950s at the same time as rising GHG emissions, which are expected to lead to increases in monsoon rainfall in future projections.

Comparing a sub-sample of CMIP5 all-forcings historical experiments with available single forcing experiments (GHG-only and aerosols-only) reveals that during the second half of the 20th century, declining rainfall in the all-forcings historical run most closely matches that in the aerosol-only run, while monsoon precipitation in the GHG-only run increases in line with theory relating to warming and model experiments of future projections. This indicates that aerosol forcing has been playing a dominant role during this historical period over South Asia, in line with the single model findings of Bollasina et al. (2011), and more general results for the NH monsoons relating to the large-scale (Polson et al., 2014).

By dividing the 24 CMIP5 all-forcings historical experiments into models including only aerosol direct effects and a group of models also including indirect effects, the MMEmeans show that rainfall decreases over South Asia in the indirect group of models, while it increases in the direct-only models. This underlines the potential for aerosol effects to have a detrimental impact on the monsoon under increasing aerosol emissions, especially when aerosol-cloud interaction processes are taken into account.

At the large-scale of the $\mathrm{NH}$, increasing aerosol concentrations cause a reduction in Northern Hemisphere temperature relative to the south, which is known to cause reductions in NH monsoons. This effect is strengthened in the indirect group of models. Thus aerosol emissions over the 20th century provide a large-scale background on which the various regional monsoons may be modified. Looking in more detail at the local effects reveals changes in large-scale horizontal moisture convergence only for direct models relating to warming from GHG. The indirect models however show minimal changes in lower-tropospheric moisture fluxes despite strong rainfall declines. This suggests involvement of local processes. Indeed examination of the collocation of sulphate aerosol loading, low-cloud cover and cloud droplet number (essential for the indirect effect to operate) indicates the operation of indirect aerosol effects over India, leading to reductions in monsoon rainfall in the present day.

These findings highlight the urgent need to understand the differences in modelled aerosol formulations present in the direct-only group of models and those incorporating indirect effects, given the large difference in response to the mon-
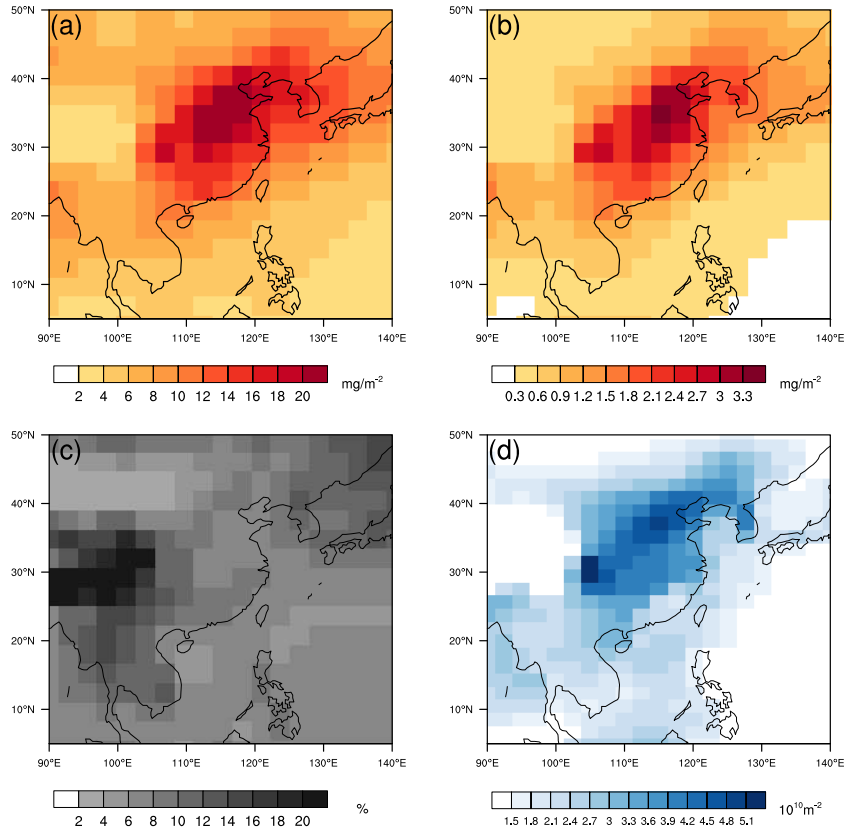

Figure 6. Same as Fig. 5, but for a domain over East Asia.

soon. The suggestion is that the inclusion of complex aerosol effects which are more faithful to the real atmospheric system yields a more powerful negative impact on the monsoon and a different response of monsoon rainfall over the historical period to that in CMIP3 (Fan et al., 2010). While we generally have more confidence in our models if the presentday simulations perform well at simulating the mean monsoon, its seasonal cycle and variability (Turner and Annamalai, 2012; Ramesh and Goswami, 2014; Sabeerali et al., 2014), a key novelty of our study is that it is only the models containing aerosol indirect effects that can reasonably be expected to represent the observed trend.

Our findings also lead to a need to understand the proportional contribution to South Asia rainfall from local aerosol against remote aerosol, given the combination of change in the large-scale background and indirect responses to the local concentration of aerosol emissions. Additionally, a further implication is that while the large late 20th century emissions of aerosol in China are enough to reduce rainfall when only direct effects of aerosol are considered, over South Asia the sulphate emissions are not large enough to reduce monsoon rainfall without indirect effects. Figure $6 a$ and $b$ show that while black carbon loading over China has a similar magnitude to India (comparing Fig. 6b and Fig. 5b), the sulphate loading over China is twice as large as that over India (comparing Fig. 6a and Fig. 5a). This supports our hypothesis that the aerosol burden over China may be large enough that even the direct radiative effects of aerosol alone are able to weaken rainfall over China during summer. Figure 6 reveals further interesting features. The maximum low-cloud cover during summer is situated over southwest China at the lee side of 
the Tibetan Plateau (the Sichuan basin), consistent with observations. This is the region in which we note the strongest increase in cloud droplet number concentration, due to the overlap of high sulphate aerosol loads and low-cloud cover (Fig. 6d). Over much of central and southeast China (where rainfall declines the most as in Fig. 3), there is weak lowcloud cover and thus the indirect effect is likely to make little difference (e.g. compare Fig. 3b and c). This configuration of low-cloud and aerosol loading over China is different from that over India.

The new experimental design in CMIP5 offers us a chance to investigate the key factors that contribute to climate change over South Asia, given the various evolving anthropogenic drivers over the historical period such as GHGs, aerosols and land-use change. However, to understand the mechanisms of how direct and indirect effects impact the South Asian monsoon, more experiments are needed to understand these effects at the process level. We also need to consider how to separate the effect of regional aerosol emissions from large-scale impacts, and to take into account the interaction between anthropogenic aerosols and natural aerosols (such as dust) in their impact on the monsoon rainfall. We will report on such experiments in a further series of studies. We also recommend that modelling groups contributing to future coordinated multi-model experiments such as CMIP6 aim to include, as standard, a more thorough coverage of single-forcing experiments.

Finally, this study has implications for future projections of monsoon rainfall. While the effects of increased carbon dioxide on the mean monsoon alone are quite clear (Turner and Annamalai, 2012), such studies are idealised. Projected emissions scenarios for the latest IPCC assessment use representative concentration pathways (RCPs), which feature declining emissions of black carbon and sulphate, including over India and China after around 2020-2040 depending upon the scenario. However, there is substantial uncertainty in future aerosol emissions. Given the role of aerosols in monsoon rainfall trends suggested here, it is possible that the future evolution of monsoon rainfall as projected by the CMIP5 models may depart significantly from current projections if the aerosol emissions do not decline as assumed in the RCPs. One study has suggested that future projections under enhanced greenhouse warming may be biased by a simulation of too much convective rainfall (e.g. Sabeerali et al., 2014), however there is no evidence that strong aerosol forcing is causing this and indeed it is suggested by other studies that inclusion of aerosol's ability to change cloud droplet number concentration (i.e., indirect effects) may give a more realistic simulation of stratiform convection (Wood, 2012).
Acknowledgements. L. Guo is funded under the NERC Changing Water Cycle (South Asia) project SAPRISE (NE/I022469/1); A. G. Turner was funded by a NERC Fellowship (NE/H015655/1) for a portion of this work. We acknowledge the World Climate Research Programme's Working Group on Coupled Modelling, which is responsible for CMIP, and we thank the climate modelling groups (listed in Table 1 of this paper) for producing and making available their model output. For CMIP the U.S. Department of Energy's Program for Climate Model Diagnosis and Intercomparison provides coordinating support and led development of software infrastructure in partnership with the Global Organization for Earth System Science Portals.

Edited by: Y. Balkanski

\section{References}

Acharya, P. and Sreekesh, S.: Seasonal variability in aerosol optical depth over India: a spatio-temporal analysis using the MODIS aerosol product, Int. J. Remote Sens., 34, 4832-4849, doi:10.1080/01431161.2013.782114, 2013.

Albrecht, B. A.: Aerosols, Cloud Microphysics, and Fractional Cloudiness, Science, 245, 1227-1230, doi:10.1126/science.245.4923.1227, 1989.

Bollasina, M. A., Ming, Y., and Ramaswamy, V.: Anthropogenic Aerosols and the Weakening of the South Asian Summer Monsoon, Science, 334, 502-505, doi:10.1126/science.1204994, 2011.

Charlson, R. J., Schwartz, S. E., Hales, J. M., Cess, R. D., Coakley, J. A., Hansen, J. E., and Hofmann, D. J.: Climate Forcing by Anthropogenic Aerosols, Science, 255, 423-430, doi:10.1126/science.255.5043.423, 1992.

Cherian, R., Venkataraman, C., Quaas, J., and Ramachandran, S.: GCM simulations of anthropogenic aerosol-induced changes in aerosol extinction, atmospheric heating and precipitation over India, J. Geophys. Res.-Atmos., 118, 2938-2955, doi:10.1002/jgrd.50298, 2013.

Dash, S. K., Kulkarni, M. A., Mohanty, U. C., and Prasad, K.: Changes in the characteristics of rain events in India, J. Geophys. Res., 114, D10109, doi:10.1029/2008JD010572, 2009.

Devara, P. C. S. and Manoj, M. G.: Aerosol-cloud-precipitation interactions: A challenging problem in regional environment and climate research, Particuology, 11, 25-33, doi:10.1016/j.partic.2012.07.006, 2013.

Ding, Y., Wang, Z., and Sun, Y.: Inter-decadal variation of the summer precipitation in East China and its association with decreasing Asian summer monsoon. Part I: Observed evidences, Int. J. Climatol., 28, 1139-1161, doi:10.1002/joc.1615, 2008.

Douville, H., Royer, J.-F., Polcher, J., Cox, P., Gedney, N., Stephenson, D. B., and Valdes, P. J.: Impact of $\mathrm{CO}_{2}$ doubling on the Asian summer monsoon: robust versus model-dependent responses, J. Meteorol. Soc. Jpn., 78, 421-439, 2000.

Ekman, A. M. L.: Do sophisticated parameterizations of aerosolcloud interactions in CMIP5 models improve the representation of recent observed temperature trends?, J. Geophys. Res.Atmos., 119, 817-832, doi:10.1002/2013JD020511, 2014.

Fan, F. X., Mann, M. E., Lee, S., and Evans, J. L.: Observed and Modeled Changes in the South Asian Summer Mon- 
soon over the Historical Period, J. Climate, 23, 5193-5205, doi:10.1175/2010jcli3374.1, 2010.

Gautam, R., Hsu, N. C., Lau, K.-M., and Kafatos, M.: Aerosol and rainfall variability over the Indian monsoon region: distributions, trends and coupling, Ann. Geophys., 27, 3691-3703, doi:10.5194/angeo-27-3691-2009, 2009.

Goswami, B. N., Venugopal, V., Sengupta, D., Madhusoodanan, M. S., and Xavier, P. K.: Increasing trend of extreme rain events over India in a warming environment, Science, 314, 1442-1445, doi:10.1126/science.1132027, 2006.

Guo, L., Highwood, E. J., Shaffrey, L. C., and Turner, A. G.: The effect of regional changes in anthropogenic aerosols on rainfall of the East Asian Summer Monsoon, Atmos. Chem. Phys., 13, 1521-1534, doi:10.5194/acp-13-1521-2013, 2013.

Jones, G. S., Christidis, N., and Stott, P. A.: Detecting the influence of fossil fuel and bio-fuel black carbon aerosols on near surface temperature changes, Atmos. Chem. Phys., 11, 799-816, doi:10.5194/acp-11-799-2011, 2011.

Joshi, M. M., Turner, A. G., and Hope, C.: The use of land/sea warming contrast under climate change to improve impact metrics, Climatic Change, 117, 951-960, doi:10.1007/s10584-0130715-6, 2013.

Kitoh, A., Endo, H., Krishna Kumar, K., Cavalcanti, I. F. A., Goswami, P., and Zhou, T.: Monsoons in a changing world: A regional perspective in a global context, J. Geophys. Res.-Atmos., 118, 3053-3065, 2013.

Krishnan, R., Sabin, T. P., Ayantika, D. C., Kitoh, A., Sugi, M., Murakami, H., Turner, A. G., Slingo, J. M., and Rajendran, K.: Will the South Asian monsoon overturning circulation stabilize any further?, Clim. Dynam., 40, 187-211, doi:10.1007/s00382012-1317-0, 2013.

Krishnamurthy, V. and Goswami, B. N.: Indian Monsoon-ENSO Relationship on Interdecadal Timescale, J. Climate, 13, 579-595, 2000

Lau, K. M., Kim, M. K., and Kim, K. M.: Asian summer monsoon anomalies induced by aerosol direct forcing: the role of the Tibetan Plateau, Clim. Dynam., 26, 855-864, doi:10.1007/s00382006-0114-z, 2006.

Lau, K. M., Kim, K. M., Hsu, C., and Singh, R. P.: Seasonal Covariability of Aerosol and Precipitation over the Indian Monsoon and adjacent deserts, GEWEX News, 18, 4-5, 2008.

Meehl, G., Stocker, T., Collins, W., Friedlingstein, P., Gaye, A., Gregory, J., Kitoh, A., Knutti, R., Murphy, J., Noda, A., Raper, S., Watterson, I., Weaver, A., and Zhao, Z.-C.: Global Climate Projections Cambridge University Press, in: Climate Change 2007: The Physical Science Basis. Contribution of Working Group I to the Fourth Assessment Report of the Intergovernmental Panel on Climate Change, edited by: Solomon, S., Qin, D., Manning, M., Chen, Z., Marquis, M., Averyt, K. B., Tignor, M., and Miller, H. L., Chap. 10, 747-846, 2007.

Misra, A., Gaur, A., Bhattu, D., Ghosh, S., Dwivedi, A. K., Dalai, R., Paul, D., Gupta, T., Tare, V., Mishra, S. K., Singh, S., and Tripathi, S. N.: An overview of the physico-chemical characteristics of dust at Kanpur in the central Indo-Gangetic basin, Atmos. Environ., 97, 386-396, doi:10.1016/j.atmosenv.2014.08.043, 2014.

Moorthy, K. K., Babu, S. S., Manoj, M. R., and Satheesh, S. K.: Buildup of aerosols over the Indian Region, Geophys. Res. Lett., 40, 1011-1014, doi:10.1002/grl.50165, 2013.
Polson, D., Bollasina, M., Hegerl, G. C., and Wilcox, L. J.: Decreased monsoon precipitation in the Northern Hemisphere due to anthropogenic aerosols, Geophys. Res. Lett., 41, 6023-6029, doi:10.1002/2014GL060811, 2014

Rajeevan, M., Bhate, J., Kale, J. D., and Lal, B.: High resolution daily gridded rainfall data for the Indian region: Analysis of break and active monsoon spells, Current Sci., 91, 296-306, 2006.

Ramanathan, V., Chung, C., Kim, D., Bettge, T., Buja, L., Kiehl, J. T., Washington, W. M., Fu, Q., Sikka, D. R., and Wild, M.: Atmospheric brown clouds: Impacts on South Asian climate and hydrological cycle, Proc. Natl. Aca. Sci. USA, 102, 5326-5333, doi:10.1073/pnas.0500656102, 2005.

Ramesh, K. V. and Goswami, P.: Assessing reliability of regional climate projections: the case of Indian monsoon, Scientific Reports, 4, 4071, doi:10.1038/srep04071, 2014.

Sabeerali, C. T., Suryachandra Rao, A., Dhakate, A. R., Salunke, K., and Goswami, B. N.: Why ensemble mean projection of south Asian monsoon rainfall by CMIP5 models is not reliable? Clim. Dynam., 45, 161-174, doi:10.1007/s00382-014-2269-3, 2014.

Saha, A., Ghosh, S., Sahana, A. S., and Rao, E. P.: Failure of CMIP5 climate models in simulating post-1950 decreasing trend of Indian monsoon, Geophys. Res. Lett., 41, 7323-7330, doi:10.1002/2014GL061573, 2014.

Sajani, S., Moorthy, K. K., Rajendran, K., and Nanjundiah, R. S.: Monsoon sensitivity to aerosol direct radiative forcing in the community atmosphere model, J. Earth Syst. Sci., 121, 867-889, doi:10.1007/s12040-012-0198-2, 2012.

Salzmann, M., Weser, H., and Cherian, R.: Robust response of Asian summer monsoon to anthropogenic aerosols in CMIP5 models, J. Geophys. Res.-Atmos., 119, 11321-11337, doi:10.1002/2014JD021783, 2014.

Sperber, K. R., Annamalai, H., Kang, I.-S., Kitoh, A., Moise, A., Turner, A., Wang, B., and Zhou, T.: The Asian Summer Monsoon: An Intercomparison of CMIP5 vs. CMIP3 Simulations of the Late 20th Century, Clim. Dynam., 41, 2711-2744, 2013.

Taylor, K. E., Stouffer, R. J., and Meehl, G. A.: An overview of CMIP5 and the experiment design, Bull. Am. Meteorol. Soc., 93, 485-498, doi:10.1175/bams-d-11-00094.1, 2012.

Turner, A. G. and Annamalai, H.: Climate change and the South Asian summer monsoon, Nature Climate Change, 2, 587-595, doi:10.1038/nclimate1495, 2012.

Turner, A. G., Inness, P. M., and Slingo, J. M.: The effect of doubled $\mathrm{CO} 2$ and model basic state biases on the monsoon-ENSO system. I: Mean response and interannual variability, Q. J. Roy. Meteorol. Soc., 133, 1143-1157, 2007.

Twomey, S.: Influence of pollution on shortwave albedo of clouds, J. Atmos. Sci., 34, 1149-1152, doi:10.1175/15200469(1977)034<1149:tiopot>2.0.co;2, 1977.

Wang, B., Liuc, J., Kim, H.-J., Webster, P., Yim, S.-Y., and Xiang, B.: Northern Hemisphere summer monsoon intensified by mega-El Nino/southern oscillation and Atlantic multidecadal oscillation, Proc. Natl. Aca. Sci., 110, 5347-5352, doi:10.1073/pnas.1219405110, 2013.

Wilcox, L. J., Highwood, E. J., and Dunstone, N. J.: The influence of anthropogenic aerosol on multi-decadal variations of historical global climate, Environ. Res. Lett., 8, 024033, doi:10.1088/17489326/8/2/024033, 2013. 
Wilks, D. S.: Statistical Methods in the Atmospheric Sciences - An Introduction, vol. 59, International Geophysics Series, Academic Press, 1995.

Wood, R.: Stratocumulus Clouds, Mon. Weather Rev., 140, 23732423, 2012.
Zhai, P. M., Zhang, X. B., Wan, H., and Pan, X. H.: Trends in total precipitation and frequency of daily precipitation extremes over China, J. Climate, 18, 1096-1108, doi:10.1175/jcli-3318.1, 2005. 